Universidad Nacional de La Plata.

Facultad de Humanidades y Ciencias de la Educación.

Centro de Investigaciones Socio Históricas

\title{
"El hombre del año 2000". Actores, discursos y políticas hacia la infancia durante la dictadura (1976-1980)
}

\author{
People in the year 2000. Players, speeches, and policies related to \\ childhood during the dictatorship (1976-1980)
}

\begin{abstract}
María Florencia Osuna *
* Universidad Nacional de General Sarmiento-CONICET/Universidad Nacional de La Plata, Argentina | florenciaosuna@gmail.com
\end{abstract}

\section{PALABRAS CLAVE}

Infancia

Última dictadura

UNICEF

Católicos

Secretaría del Menor y la Familia

KEYWORDS

Childhood

Last dictatorship

UNICEF

Catholic

Secretary of Children and Families

\section{RESUMEN}

Este artículo se propone reconstruir un conjunto diverso de iniciativas, representaciones y redes de actores vinculado a la infancia que tuvo lugar durante la última dictadura argentina (1976-1980). Por un lado, analiza la conexión imaginaria existente en esos años entre los niños, el futuro y la tecnología, que era compartida por actores variopintos. En relación con esto, para la dictadura, la infancia representaba un campo potencial de incertidumbre que era necesario controlar y dirigir. Por otro lado, el trabajo estudia la conmemoración del "Año internacional del niño" de 1979 dando cuenta de las influencias internacionales de la Iglesia y también de UNICEF en la realización del evento. También muestra la diversidad de actores y de propuestas hacia la infancia que tuvo lugar en el espacio público en los años más represivos del terrorismo de Estado.

\section{ABSTRACT}

The purpose of this article is to reconstruct a varied set of initiatives, representations, and networks of players related to childhood during the last dictatorship in Argentina (1976-1980). On the one hand, we analyze the imaginary connection between children, the future, and technology in those years, which was shared by very mixed players. In this regard, for the dictatorship, childhood represented a potential field of uncertainties which needed to be controlled and monitored. On the other hand, this paper studies the commemoration of the "International Year of the Child" in 1979, accounting for the international influence of the Catholic Church and UNICEF to carry out the event. It also shows the wide variety of players and proposals for childhood in the public sphere during the most repressive years of State terrorism. 


\section{Introducción}

Este artículo reconstruye y estudia un conjunto de discursos e iniciativas frente a la niñez desarrollado desde los ámbitos estatal y social durante la última dictadura argentina, en el marco del diagnóstico general del gobierno y de la Iglesia católica sobre la crisis de la familia tradicional. En 1974 había comenzado a difundirse un discurso biologicista sobre la familia que la concebía como la "célula básica de la comunidad" de un "cuerpo social" que se creía infectado por el "virus subversivo". Estas representaciones se consolidaron institucionalmente a partir del golpe de Estado de 1976 y justificaron diferentes iniciativas del régimen dictatorial.

Distintos funcionarios civiles y militares consideraban que la integridad de la familia como unidad moral indisoluble sólo se lograría si se evitaba el ingreso de las ideas “disolventes” controlando, particularmente, a las "secciones débiles” de la pared de la "célula”: los niños y jóvenes de la familia (Filc, 1997). Se sostenía que por medio de ellos se propagaba el virus de la "subversión” y los responsables de que eso no ocurriera eran los padres y las madres. En este marco, la categoría de "situación de riesgo físico y moral"- utilizada a lo largo del siglo XX para definir la suerte de los menores y sus familias- se redefinió en función de la "lucha antisubversiva” (Villalta, 2005,2009, 2013, 2016; Villalta \& Regueiro, 2015). A partir de este diagnóstico, se encararon distintas iniciativas, desde jornadas de capacitación sobre los "roles" dentro de la familia hasta la creación de un Cuerpo de Vigilancia Juvenil para garantizar el control de los menores en la vía pública (Osuna, 2016).

Los niños también eran asociados con el "futuro" y, en ese sentido, representaban un campo potencial de incertidumbre que era fundamental controlar y dirigir para que se transformaran en los hombres, ciudadanos y dirigentes del mañana. Existía un consenso bastante difundido entre los principales actores a cargo del problema de la infancia acerca de que el contenido de la educación debía basarse en un ideario católico y nacionalista (Guitelman, 2006; Rodríguez, 2011; Rodríguez \& Lvovich, 2011).

Aún así, en este trabajo trataremos de expandir el repertorio de actores y discursos sobre esta problemática. En relación con esto, veremos, por un lado, que la asociación niño-futuro fue compartida por actores centrales de diversa posición ideológica: desde el presidente de facto Jorge Rafael Videla, hasta el pediatra de vanguardia Florencio Escardó. Por otro lado, buscaremos evidenciar, a través del análisis de la conmemoración del “Año internacional del niño”, en 1979, que los discursos predominantes en la escala nacional dialogaban con las iniciativas de dos grandes instituciones: la Iglesia católica, a través del Vaticano, y el Fondo de las Naciones Unidas para la Infancia (UNICEF). En los eventos realizados en Argentina en el marco de la celebración del "Año Internacional del Niño y la Familia”, los espacios, las actividades y los actores fueron bastante diversos. En ese sentido, reflexionaremos acerca de la existencia de distintas propuestas para los niños: desde la socialización autoritaria en valores de las Fuerzas Armadas y la Iglesia, hasta actividades basadas en el desarrollo de la creatividad y el juego. Tanto en el espacio público como dentro de algunas áreas de la política como la que estamos analizando, existían distintos actores, pero sobre todo múltiples imaginarios que coexistieron sin conflicto evidente.

\section{Los hombres del año 2000}

En el año 1978, tres “niños periodistas” de 12 años que formaban parte del programa televisivo de Canal 13 llamado "Buenos Anuncios” entrevistaron a Videla. 1 En el encuentro le preguntaron “¿cuál será el país del año 2000 que nos dejarán nuestros mayores?” y Videla respondió:

Es evidente que conversar con un niño es, en alguna medida, dialogar con el futuro y no les puede caber tampoco duda ninguna que ustedes, hoy niños, van a ser los dirigentes del año 2000. Entonces, al dialogar con ustedes yo estoy hablando con ese futuro, yo estoy hablando 
con el año 2000 (La Nación, 7/8/1978).

Esa representación del niño como conexión con el futuro, que invariablemente se situaba siempre en las puertas del próximo milenio, en potencia podía implicar un riesgo -si los padres y los responsables de la educación de los niños cometían errores- o la perpetuidad del ideal de Nación que deseaba la dictadura. Esto también nos permite comprender la centralidad de las enérgicas acciones encaradas por el Estado y el laicado católico frente a la niñez, o sea, “el futuro de la patria”. Seguidamente, en la entrevista el presidente de facto retomó dos vectores de ese clima de época, es decir, la relación del futuro tecnológico con los valores católicos tradicionales:

Lamentablemente, cuando pensamos en la Argentina 2000 (...) imaginamos ciudades flotantes, naves aeroespaciales, en un tremendo desarrollo de la electrónica y la comunicación, pero nunca pensamos como será un hombre del año 2000. El hombre del año 2000 -dijo seguidamente el presidente de la Nación-las mujeres del año 2000, los tenemos acá presentes, los estamos haciendo hoy y por esto va este mensaje a este chico que hoy tiene que ser el hombre del año 2000, para que acepte el rol fundamental de ser semilla (La Nación, 7/8/1978).

Los "niños periodistas” en una de las variadas canciones que entonaban a coro -escritas por Jack Feldbaum, productor del mencionado programa televisivo "Buenos Anuncios"- llamada "Suplemento 2000", afirmaban desear en el año 2000 una "Argentina, grande y moderna, con gente muy noble y espíritu creador”; "la ciencia y la técnica muy avanzadas, puestas al servicio de la humanidad” y se reconocían como "los niños de

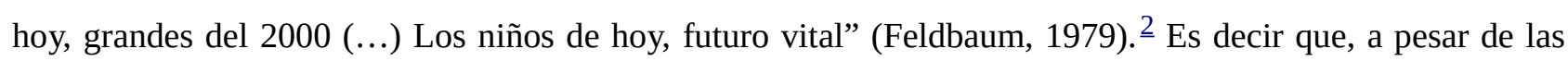
particularidades de las iniciativas de la dictadura hacia los niños, nuevamente, este discurso que ligaba niñofuturo-tecnología y que lo ubicaba en un terreno de incertidumbre no sólo configuraba las percepciones de los actores estatales, ni tampoco se ligaba a un ideario conservador necesariamente. Por ejemplo, Escardó, el mencionado pediatra, sanitarista e intelectual de vanguardia en los años sesenta y setenta, tenía una mirada diferente y heterodoxa en relación a la manera en que se debía encarar la pediatría. ${ }^{3}$ El diario La Nación otorgaba un espacio importante a su opinión. Sus notas funcionaban como un contrapunto y, a veces, como complemento de los discursos predominantes sobre los niños y la familia. Por un lado, Escardó estaba en desacuerdo con la idea de familia como “célula básica de la comunidad” y es, quizás, la única voz pública disonante sobre este tema con la que nos hemos encontrado. ${ }^{4}$ A diferencia de los actores públicos ligados a la dictadura, consideraba que esa imagen estática de la familia y la sociedad como un tejido se contradecía con los cambios que efectivamente se produjeron en la sociedad y en la familia, y que ya resultaba difícil “moldear” a ese niño portador de futuro:

Poco a poco y actualmente a pasos agigantados el recinto familiar ha visto sus muros perforados y aun destruidos por agentes externos a su antigua y decantada misión de molde y pauta de las generaciones futuras personificadas en el niño. A ello se suma la total imposibilidad de imaginar, siquiera sea someramente, el paisaje futuro, hoy en manos del poder atómico que, como lo ha demostrado González Muñoz, es ya superior e independiente de tal o cual nación (La Nación, 22/12/1979).

Aquí, nuevamente, aparece una asociación entre niño-futuro y tecnología, y el campo de la incertidumbre está vinculado con las características de las nuevas generaciones, pero también con el "paisaje futuro, hoy en manos del poder atómico”. En ese marco de grandes transformaciones, los niños de la época son descriptos por Escardó como "niños con mentalidad cósmica” 
niño) se hace capaz de trascender el tiempo y el espacio. Como hemos llegado al cosmos (satélites artificiales, viaje a la luna, astronáutica, relatividad einsteniana) están naciendo y creciendo niños con mentalidad cósmica. Esta evolución es tan esencial que el futuro de la humanidad depende de ella. Toda nuestra obligación consiste en esforzarnos en reconocer su presencia y en respetar sus manifestaciones que nos parecen desusadas sólo porque no corresponden a un canon ya perimido (La Nación, 22/12/1979).

En esta línea, encontramos también otras notas de Escardó en las que plantea el problema de qué hacer con los niños y discute la visión que expresaba Videla, pero desde el lugar de los cambios tecnológicos y la visión futurológica de la sociedad que confirman las percepciones de la época. Esta reafirmación constatada fundamentalmente con más nitidez en los más jóvenes de la familia, también estaba vinculada con la repercusión de las variables tecnológicas en la sociedad, pero en los discursos de Escardó adquirían una dimensión que rozaba lo implacable y trascendental. En este sentido, el cambio de época se manifestaba en que los "niños cósmicos” que nacían en los setenta eran los "hijos de Einstein", mientras que las generaciones anteriores eran los "hijos de Newton"

...es decir de un mundo lineal y pictórico en el que todo estaba bien; el tiempo estaba bien, el espacio estaba bien y si la ley de la atracción de los cuerpos se proclamó universal, no fue porque los terrícolas debíamos necesariamente sentirnos parte del Universo, sino porque en el Universo las cosas sucedían como en la Tierra, para paz y gloria del Universo (La Nación, 31/08/1979).

Sin embargo, "el Gato con Botas y La Bella Durmiente no fascinan demasiado a los niños de hoy, que se sienten mucho más cerca de Superman y de esa triste caricatura del hombre cotidiano que es el Pato Donald. Urge, pues, hablarles de Alberto Einstein” (La Nación, 31/08/1979).

Las implicancias de las representaciones expresadas por Videla y Escardó son distintas, están enunciadas por dos actores muy disímiles, pero nos permiten ver algunos elementos del imaginario de la época que, en algún sentido, repercutían en el tratamiento sobre la problemática de la infancia de la dictadura. El ministro de Bienestar Social, Jorge Fraga, en el marco del “Año internacional del niño y de la familia” de 1979, afirmó: "el Proceso de Reorganización Nacional señala como prioridad máxima la custodia y preservación para las generaciones futuras de los auténticos valores cristianos y morales de la familia argentina”. En este sentido, el niño-futuro debía ser formado en los

...auténticos valores, que son patrimonio de nuestra nacionalidad y de nuestra forma de ser, deberán ser y serán preservados a toda costa. Ello es un compromiso irrenunciable de las Fuerzas Armadas y de quienes coparticipen hoy en la tarea de gobernar. Teniendo en cuenta esos objetivos, mirando al futuro, preservando el presente y rescatando los valores del pasado, es que brindaremos nuestro esfuerzo para que esa niñez pueda desarrollarse en paz y felicidad (Boletín MBS 117-118, 25/12/78-1/01/79).

En esta dirección, a lo largo del año 1979, se realizaron varias jornadas que, por lo general, giraban en torno a dos temáticas amplias: “el niño y sus necesidades” y “paternidad responsable”. Estos eventos se llevaban a cabo en diversas instituciones privadas y oficiales, como el Colegio de Escribanos, la Universidad de Belgrano y el Centro Cultural del Teatro San Martín. En ellas participaban representantes de distintas organizaciones oficiales, privadas, religiosas y laicas católicas con ponencias sobre las temáticas señaladas, y los discursos de apertura y cierre estaban a cargo de las autoridades del Ministerio de Bienestar Social (MBS). En el primer seminario sobre "el niño y sus necesidades” realizado en el archivo del Colegio de Escribanos, en Buenos Aires, participaron 130 personas y se presentaron 35 ponencias. Se trataron temas como:“las familias como ámbito natural del niño”, “el niño y la salud”, “el niño y la escuela”, “el niño y la 
recreación”, “el niño y los ámbitos socio-laborales y ético-religiosos” y “el niño carenciado”. La difusión de la ideología del régimen en lo concerniente a la familia era fundamental en estas iniciativas:

En consecuencia promocionamos no sólo programas asistenciales y campañas de educación familiar que esclarezcan los roles de sus integrantes, los objetivos que puedan alcanzar a través del amor, del respeto, del diálogo y de la colaboración solidaria. Toda acción que contribuya a que la familia siga teniendo vivencia y vigencia en nuestro futuro debe merecer particular atención del Estado (Boletín MBS 117-118, 25/12/78-1/01/79).

El "esclarecimiento" de los roles al interior de la familia era un aspecto fundamental de estas políticas, ya que los padres no sólo eran considerados, como decíamos, los responsables por el comportamiento de los niños, sino también frente a la integridad de la "célula básica de la comunidad", la consecuente salud del “cuerpo social” y, por ende, el "futuro de la patria”. En este sentido, luego de los seminarios regionales realizados en adhesión al "Año del niño y la familia" en torno de los temas "el ejercicio responsable de la paternidad” y “el niño y sus necesidades”, en sus conclusiones, la subsecretaría del Menor y la Familia afirmaba

Sobre el niño y sus necesidades se propone difundir la importancia del desempeño de las funciones paterna y materna para el equilibrio del hogar y el desempeño normal del niño, considerar y analizar los factores que intervienen en los problemas de dinámica familiar e instrumentar sistemas de orientación y tratamiento adecuados a nuestra problemática ( $L a$ Nación, 15/12/1979).

Junto con esto, se proponía "fomentar el diálogo a los efectos de que los valores transmitidos por la familia no fueran desvirtuados por posibles influencias negativas del medio social” (La Nación, 15/12/1979). Las iniciativas para reforzar los roles paternos y el control sobre los niños eran diversas: propagandas mediáticas, jornadas de discusión, cursos de capacitación, talleres, exposiciones feriales e, incluso, se conformó un enigmático "Cuerpo de Vigilancia Juvenil”트 del que tenemos algunos pocos indicios, pero que es ilustrativo de las diversas políticas hacia la infancia (Osuna, 2016).

Aún así, en este marco autoritario, como ya observamos y también desarrollaremos en los próximos apartados, junto a las propuestas de los actores militares y católicos, hubo una paleta más amplia de miradas y actividades destinadas a la niñez. Los festejos del “Año internacional del niño y la familia” nos permitirán seguir analizando ese entramado complejo.

\section{Influencias transnacionales en las políticas hacia los niños: el “Año internacional del niño y la familia”.}

$\mathrm{Al}$ igual que en otros momentos del siglo XX argentino, algunas iniciativas y representaciones ligadas a los niños del último régimen argentino de facto abrevaron en dos universos con características diferentes: el de los organismos internacionales y el Vaticano.

En los años sesenta y setenta, entonces, confluyeron dos conjuntos diferentes de actores, propuestas e ideas que coincidían en su preocupación por los niños, pero se materializaban en distintas explicaciones, objetivos y metodologías. Por un lado, UNICEF encuadraba sus diagnósticos e inquietudes por la infancia en los países subdesarrollados, justamente, en el problema del desarrollo económico y social, tópico muy transitado durante la segunda mitad del siglo XX (Altamirano, 1998; Aguirre, 2010). Este organismo afirmaba que "los problemas de la niñez en América Latina están ligados a la pobreza y a la desigualdad en la distribución de los frutos del desarrollo”. En este sentido, para resolver los problemas de la infancia se consideraba necesario 
“cambiar las condiciones socioeconómicas que generan la pobreza” (La Razón, 25/2/1979). Para que los Estados revisaran sus políticas de bienestar infantil, en el año 1976, por medio de la resolución № 31/169, la ONU decidió que el año 1979, en ocasión de celebrarse el vigésimo aniversario de la Declaración de los Derechos del Niño, sería declarado “Año internacional del Niño” y se invitaba a los gobiernos de los diferentes países a unirse y desarrollar políticas que beneficiaran a este sector de la población. Se actuaba con la convicción de que las políticas sociales, económicas y culturales a favor de los niños también contribuirían al desarrollo económico nacional. Los objetivos prioritarios de las distintas resoluciones vinculadas con esta iniciativa, eran dos:

-Suministrar un marco para promover el bienestar de los niños y acrecentar la conciencia de las autoridades y el público acerca de las necesidades especiales de éstos

-promover el reconocimiento de que los programas en beneficio de los niños deben ser parte integrante de los planes de desarrollo económico y social con miras a la realización, a largo y a corto plazo, de actividades sostenidas en beneficio de los niños en los planos nacional e internacional (Resolución ONU 31/169, 1976; Boletín MBS 19, 26/2/1979).

Las autoridades nacionales le otorgaron importancia a la decisión de este organismo internacional y, por medio del Decreto No 549/79 del Poder Ejecutivo Nacional, decidieron que el año 1979 en el ámbito nacional sería el "Año internacional del niño y la familia” (Decreto 549/79, 13/03/1979). El ministro de Bienestar Social, Fraga, explicaba que "las Naciones Unidas han proclamado este año como el 'año del niño' y nosotros hemos considerado -teniendo en cuenta que tal declaración deja librada a cada país la forma de la celebración- adicionarle en el nuestro lo concerniente a la familia”. En las argumentaciones del ministro acerca del porqué de la importancia de la "familia" encontramos la clave explicativa de la manera en que la Iglesia católica también participó a la hora de definir la forma que adquirieron las celebraciones. La adhesión a esta iniciativa de UNICEF, según Fraga, se fundamentaba en el propósito del "Proceso de Reorganización Nacional” de señalar "como prioridad máxima la custodia y preservación para las generaciones futuras de los auténticos valores cristianos y morales de la familia argentina”:

Porque hemos vivido una etapa en que se pretendió interferir los auténticos valores de la familia, distorsionando su finalidad y autenticidad. En segundo lugar, porque no se puede concebir al niño separado de ella. Nuestros auténticos valores, que son patrimonio de nuestra nacionalidad y de nuestra forma de ser, deberán ser y serán preservados a toda costa. Ello es un compromiso irrenunciable de las Fuerzas Armadas y de quienes coparticipen hoy en la tarea de gobernar. Teniendo en cuenta esos objetivos, mirando al futuro, preservando el presente y rescatando los valores del pasado, es que brindaremos nuestro esfuerzo para que esa niñez pueda desarrollarse en paz y felicidad. Para ello el ministerio a mi cargo, a través de la Secretaria de Acción Social y con el apoyo de otros sectores del gobierno y del ámbito privado, llevará a cabo un programa de integración del niño y la familia, cuyos detalles daremos a conocer al país (Boletín MBS 117-118, 25/12/1978-1/01/1979).

En otro documento oficial, se insistía con que "nuestro país se enorgullece de contar con una familia fuertemente arraigada a nuestras más queridas tradiciones”. En relación con eso, se afirmó que es imposible separar al niño de la familia "por lo que resulta indispensable para proteger a éste, realizar constantes acciones para la defensa y la promoción de la familia, tal como exhortara a hacerlo, hace muy pocos días y desde Puebla, su santidad Juan Pablo II” (Boletín MBS 121-122, 19-26/2/1979). Esta cita nos resulta relevante ya que remite a otra dimensión transnacional, en este caso la Doctrina Social de la Iglesia. Fraga estaba haciendo mención a la Tercera Conferencia General del Episcopado Latinoamericano (CELAM) que se realizó en enero de 1979 en Puebla, México, con la presencia del Papa Juan Pablo II, quien pretendía recomponer la unidad y jerarquía de la Iglesia universal (Di Stefano \& Zanatta, 2009, p. 551). En el marco de 
la conferencia del CELAM, el Papa pronunció una homilía en la que habló, entre otras cuestiones, de la importancia de la familia, de la que se hicieron eco los funcionarios y los diarios de tirada nacional locales. En relación con esto, se pronunció contra "los intentos indiscriminados de reducir el aumento de población en América Latina” y “las formas artificiales de control de la natalidad”. Señaló que muchos de los niños que nacían en América Latina enfrentaban una vida de pobreza, padecimientos y enfermedades, "la Iglesia pide a los gobiernos que adopten políticas (...) a fin de defender a las familias contra esos males", ya que "no se trata de reducir el índice demográfico a cualquier precio, sino de crear condiciones favorables a la existencia de familia sanas y equilibradas". También se refirió al divorcio: “La Iglesia es consciente, en efecto, de que en estos tiempos la familia afronta en América Latina serios problemas. Últimamente algunos países han introducido el divorcio en su legislación, lo cual conlleva una nueva amenaza a la integridad familiar”. Asimismo, concibió a los niños como el "porvenir de esas naciones y esperanzas para el futuro", se lamentaba que un número alarmante nazca "en hogares sin ninguna estabilidad o, como se les suele llamar, en 'familias incompletas'”. Finalmente, las cuestiones socioeconómicas, ligadas al desarrollo, también ocupaban su peso en el diagnóstico del Sumo Pontífice y confluían con las propuestas de UNICEF en algunos aspectos:

Además, en ciertos lugares del "continente de la esperanza”, esta misma esperanza corre el riesgo de desvanecerse, pues ella crece en el seno de las familias, muchas de las cuales no pueden vivir normalmente porque repercuten particularmente en ellas los resultados más negativos del desarrollo: índices verdaderamente deprimentes de insalubridad, pobreza y aún miseria, ignorancia y analfabetismo, condiciones inhumanas de vivienda, subalimentación crónica y tantas otras realidades no menos tristes. En defensa de la familia, contra estos males, la Iglesia se compromete a dar su ayuda e invita a los gobiernos para que pongan como punto clave de su acción una política sociofamiliar inteligente, audaz, perseverante, reconociendo que ahí se encuentra, sin duda, el porvenir -la esperanza-del continente (La Nación, 29/01/1979).

Teniendo en cuenta este contexto general e internacional, a continuación, analizaremos los actores, los imaginarios y las actividades que se llevaron a cabo en Argentina, en el marco de los festejos por el "Año Internacional del Niño y la Familia”, atendiendo a las particularidades del país en esos años: una dictadura fuertemente represiva, basada en el terrorismo de Estado, en la que el "mundo católico" y militar hegemonizaban los discursos y las prácticas relacionada con los menores y sus familias.

a. La "semana del niño": actores y actividades en el espacio público

El análisis de los eventos llevados a cabo en el contexto de la "semana del niño" durante "el Año Internacional del Niño y la Familia” nos muestra distintas cuestiones. En primer lugar, la confluencia de prácticas y actores diversos, algunos de los cuales se englobaban en el mismo universo ideológico de la dictadura y otros que no respondían estrictamente al mismo. Un conjunto de actividades que se caracterizó por tener un tinte elitista, católico y autoritario convivió con otras propuestas de carácter lúdico y creativo. Entre los organizadores e impulsores de estos eventos, sin embargo, encontramos, mayormente, a miembros de la elite tradicional, militares y religiosos. Como veremos luego, entre las actividades más ligadas al imaginario conservador/militar prevalecían aquellas relacionadas a los deportes de elite, desfiles militares, exposiciones y demostraciones de animales adiestrados, visitas a instalaciones militares y misas católicas.

La composición de la “comisión asesora” para el “Año del niño y la familia” (Boletín MBS 125-126-127, 19-26 /03/1979-2/04/1979), nos permite observar que sus miembros pertenecían a la elite tradicional argentina, tenían un desempeño experto en profesiones liberales (abogados o médicos), practicaban de manera cuasi profesional algunos deportes con sesgo clasista como el rugby, el golf, el tenis y el polo, y, además, eran todos hombres. El secretario del Menor y la Familia del MBS, el abogado Florencio Varela, 
quien pertenecía a ese tradicional sector socioeconómico, también era árbitro de rugby. En una entrevista afirmó, en relación a las familias que vivían en departamentos reducidos en la ciudad, que "es también importante saber usar el ocio en una sociedad que no tiene la menor idea de cómo utilizarlo. El deporte es una buena solución para el tiempo libre de los chicos, porque la actividad en un hábitat estrecho convierte al ocio en una bomba de tiempo" (La Nación, 17/05/1979). El sentido de la educación física y el deporte de fines del siglo XIX ligado al disciplinamiento militar de los cuerpos y la división de género fue reforzado durante la última dictadura. ${ }^{\underline{7}}$ En este marco, es posible entender la relevancia otorgada a la actividad física en la utilización del tiempo libre, más ligada al disciplinamiento social que a la recreación. Sin embargo, creemos que lo más llamativo de la composición del grupo de "asesores" es su carácter de clase, del que derivaron otros rasgos de la elite argentina, como la práctica de esos deportes. Al igual que Varela, el médico Ezequiel Holmberg, había pertenecido al MBS durante el gobierno de Juan Carlos Onganía, como secretario de Salud, y era jugador y árbitro de rugby. También encontramos al abogado y juez de la Cámara Nacional

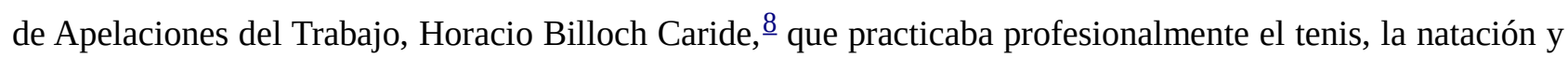
el waterpolo, y en los años estudiados se desempeñó como director de Asociación Argentina de Tenis. Asimismo, integraba la comisión el abogado (Universidad Nacional de La Plata) radical Julio Ernesto Cassanello, quien, desde 1975, fue consejero del Comité Olímpico Argentino, dirigió el Quilmes Atlético Club, fue secretario general de la Asociación del Fútbol Argentino (AFA) y muy cercano al círculo de Julio Grondona. También fue el presidente de Confederación Argentina de Taekwondo y en los últimos años de la dictadura llegó a ser intendente de Quilmes de la mano del General Ibérico Saint Jean (Página 12, 24/04/2005). El abogado (Universidad de Buenos Aires/Harvard) radical Enrique Olivera, ex jefe de gobierno de la ciudad de Buenos Aires, era socio del Jockey Club y en años posteriores accedió a la presidencia de la institución (Página 12, 5/5/2014; La Nación, 4/5/2014). El abogado Santiago Uriel O’Farrell, perteneciente a una de las familias argentinas ligada a los sectores agroexportadores del siglo XIX y a la "generación del 80", también formó parte de los sectores más tradicionalistas del mundo católico del siglo XX, integrando los Cursos de Cultura Católica y el Colegio de Abogados de Buenos Aires, fue jugador de Rugby y también vicepresidente de la Asociación Argentina de Polo (La Nación, 04/11/1999). El Subsecretario de Deportes del MBS, Profesor Alberto Dallo, también integraba la lista de la Comisión. Aunque tenía un perfil un poco distinto. Nacido en La Pampa, había estudiado educación física en el Instituto Nacional de Educación Física "General M. Belgrano”, al realizar estudios de gimnasia en diferentes países, se convirtió en una figura muy importante en el entrenamiento deportivo dentro de la Escuela Naval Militar,

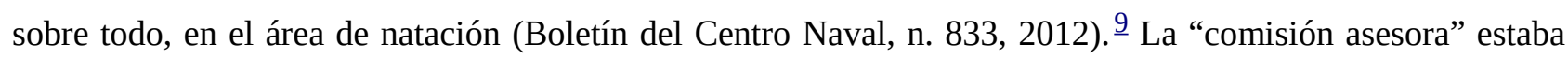
presidida por el secretario de Acción Social, Carlos Izzo Puebla, y también la integraba, como única mujer, la subsecretaria del Menor y la Familia, la abogada (UBA) Graciela Borzone. Como se observa, la composición de esta comisión acentuaba los rasgos elitistas, católicos, tradicionalistas -y podríamos agregar patriarcalesde las políticas hacia la familia.

Otro de los actores centrales en estos años que colaboraba con el MBS -a partir de una labor orientada a la niñez- fue Oscar Schiariti, miembro fundador junto con Francisco Rizzutto de la Liga Pro Comportamiento Humano definida como "una institución sin fines de lucro cuyos ideales eran difundir hermandad y respeto en la sociedad” (Rodríguez, 2009). El 31 de marzo se celebraba “el Día del Comportamiento Humano” y esta iniciativa era cumplida en el seno del MBS y de Educación en esa fecha. $\underline{10}$ Como explica Laura Graciela Rodríguez, desde 1960 el presidente de la Liga era el hijo de Rizzuto, Francisco "Pancho” Rizzuto, que en 1965 era además el vicepresidente de la Federación Argentina de Entidades Democráticas Anticomunistas (FAEDA), una agrupación nacionalista de derecha. Aunque la Liga también fue integrada en las iniciativas relacionadas con la familia del Ministerio, fue Schiariti quien adquirió un gran protagonismo, sobre todo en 1979, en ocasión de celebrar "el año del niño y la familia”. Schiariti tenía los títulos de Maestro, Profesor de Educación Física, Profesor de Letras, fue Procurador Universitario Nacional y Profesor de Cursos de la 
Organización de los Estados Americanos (Recreación y comunicación). Ejerció como docente en el nivel primario y secundario, y realizó labores en distintas entidades no gubernamentales de índole social y cultural, de tendencia filantrópica y caritativa. Se incorporó a la Liga Pro Comportamiento Humano fundada en Buenos Aires el 19 de abril de 1960, bajo el lema "Por la vigencia de los valores éticos y espirituales". Dentro de su estructura ocuparía, entre otros, los cargos de Secretario General y Coordinador de Acción Educativa. Fue coautor con Rizzutto del Manual Pro-comportamiento humano. Presidió la Comisión Permanente "Día del niño" creada en 1959 que organizaba espectáculos para esa fecha y regalaba juguetes a niños hospitalizados, y, junto con esto, promovió la creación de la "semana del niño”. $\underline{11}$ Dentro de la misma, organizó tareas de acción deportiva y de colaboración social con hospitales y centros asistenciales a la minoridad. También invitaba a los Institutos de la Minoridad y la Familia de la Capital Federal para que sus niños actúen en diversos deportes y en actividades creativas en el Parque Rivadavia, en el Zoológico de Buenos Aires, en el Italpark, en el Campo Hípico de Polo, entre otros, y entregaba premios y diplomas a todos los participantes. En el año 1962, Schiariti fundó de la Comisión Ejecutiva Permanente "El Niño y la Televisión” y presidió 32 congresos argentinos y 4 internacionales sobre la especialidad.

Resulta evidente, que al menos desde los años sesenta, ya se venían realizando varias de las actividades hacia los niños impulsadas por la Liga que reseñamos. Sin embargo, durante la dictadura, en el marco de la "Subsidiariedad del Estado” y de la hegemonía de los sectores católicos y los grupos más conservadores de la sociedad, van a adquirir una mayor institucionalización y gran visibilidad. En este sentido, a lo largo de este gobierno, pero fundamentalmente en el año 1979, Schiariti participó activamente en las iniciativas del Estado y, particularmente, del MBS ligadas con los niños (Anich, s/f).

Cabe señalar que las actividades propuestas por los diferentes sectores convivían, por lo general, en los mismos espacios. Como señalábamos anteriormente, existía un universo práctico e ideológico pensado y ofrecido a los niños por los sectores militares y católicos que ha sido escasamente abordado. Sin embargo, la tónica de los eventos coincide con el universo destinado a la infancia que analizan Daniel Lvovich y Rodríguez (2011) en su estudio de la creación de la Gendarmería Infantil (GI) en este período. Los autores han señalado que la GI fue "un intento de incidir en la socialización de los niños y jóvenes por parte de un sector del régimen militar”. El objetivo era mantener a niños y jóvenes "alejados de la subversión”, estableciendo lazos entre este sector de la población y las fuerzas de seguridad, socializándolos en valores, principios y ceremonias propios de esas fuerzas. Según la declaración de un comandante mayor, la GI no se pensó para "reemplazar a la familia, ni a la Iglesia ni a la escuela, sino que todo lo contrario". Su interés radicaba en "completar, coadyuvar y colaborar con las tres instituciones bases de nuestra sociedad" (Lvovich \& Rodríguez, 2011). En este sentido, es evidente la coincidencia de este discurso militar con el expresado por el gobierno. El comandante referido explicaba que el objetivo de la GI era "ocupar sus tiempos libres [el de los niños] en algo útil y acrecentar el espíritu patriótico de ellos, quienes constituyen el futuro del país” y, en este sentido, "aniquilará el ocio, que es el principal factor de las inclinaciones malsanas". Discurso que, a su vez, coincidía con el de algunos padres de familia entusiasmados con la iniciativa: "Nuestros hijos recibirán de Gendarmería Nacional un complemento valioso para la familia y la formación de los futuros ciudadanos” (Lvovich \& Rodríguez, 2011).

En este sentido, varias actividades desarrolladas durante "el año del niño y la familia” respondían a estos propósitos de las Fuerzas Armadas y de la Iglesia, que a su vez actuaban en conjunto. En ese marco, el General Reynaldo Bignone, haciendo referencia a la campaña sobre "niñez y ejército" $\underline{12}$ afirmó "la victoria sobre la subversión debe consolidarse día a día en el alma del niño” (La Nación, 6/7/1979). Entre las actividades realizadas en sintonía con este ideario, la Marina organizó una visita de los niños al rompehielos Almirante Irizar y el comando del buque entregó -al ganador de una regata de vela- un cuadro con la nave “como premio al espíritu marino de los niños”. Por su parte, el Círculo de Suboficiales de la Fuerza Aérea 
organizó en su sede central un evento con "espectáculos al aire libre”, por ejemplo, el aterrizaje de un helicóptero de la Fuerza con payasos y magos que distribuían golosinas y juguetes (La Nación, 5/8/1979). Incluso el Comité Ejecutivo permanente “el niño y la TV”, presidido por Schiariti, clausuró la celebración con un acto realizado en el Campo Hípico Militar que comenzó con "un carrusel de bandas militares” y finalizó con "la Retreta del Desierto”. $\underline{13}$ A su vez, coros de niños entonaron villancicos navideños en siete idiomas y se efectuó una suelta simbólica de palomas y globos de colores. Finalmente, “un equipo de perros ovejeros alemanes adiestrados efectuaron demostraciones” (La Nación, 29/12/1979).

La Iglesia Católica, por su parte, también organizó numerosas misas para celebrar el acontecimiento ( $L a$ Nación, 5/8/1979). La provincia de Tucumán asumió con creces esta conmemoración y es un buen ejemplo para ver cómo estas prácticas y representaciones se pusieron en juego, según las directivas emanadas del orden nacional. En esa provincia se creó la Comisión Tucumana Año Internacional del Niño y la Familia (COTAIN) y, al igual que a nivel nacional, se desarrollaron dos actividades centrales: ferias con exposiciones y jornadas de discusión. En julio de 1979, se llevó a cabo la I Feria Nacional del niño (en los campos de la Sociedad Rural local, con auspicio de la Federación Económica Provincial, la Cámara del Vestido y la Asociación de Dirigentes de Ventas) (La Nación, 7/4/1979) y, en agosto, las Jornadas de la Niñez, organizadas por el COTAIN y patrocinadas por el arzobispado de Tucumán (La Nación, 5/8/1979). $\stackrel{14}{\text { La feria }}$ implicó la existencia de stands con "juguetes, alimentos, material fotográfico, cinematográfico y de lectura; objetos musicales y otros de tipo pedagógico, vestimentas, material sanitario y utilaje para decoración y amoblamiento” y supuso la organización de Jornadas de discusión sobre el problema de los niños y sus familias para analizar "de qué manera el medio socioeconómico, el clima cultural, la situación sanitaria y las normas legales en vigencia favorecen o dificultan el mejor desarrollo del niño y su familia”. Aunque también hubo desfiles de bandas militares, exposiciones de animales y presentaciones de coros infantiles. El vicepresidente de la comisión organizadora era un eclesiástico, el presbítero José Carrone que señaló que “mientras no organicemos bien la familia tendremos problemas con los jóvenes", anticipó el apoyo del Arzopisbado de Tucumán tanto a la Feria como a las jornadas y sostuvo que "en el seno de la familia está, frecuentemente, el germen que llevará al niño, más tarde, a la delincuencia o a la droga, o que permitirá que se convierta a su turno en un ciudadano útil y adaptado a la sociedad” (La Nación, 5/8/1979).

Sin embargo, como dijimos, también se proponía a los niños actividades recreativas basadas en el juego, el baile, la música, las artes plásticas y los concursos de manchas. Entre éstas, algunas eran más espontáneas y estaban basadas en la improvisación y otras, sin embargo, como los shows de payasos y algunos musicales, eran protagonizadas por personajes ligados a la religión católica. No sabemos si estas actividades se realizaban en otros contextos históricos, ya que no tenemos registros, aunque es probable. Llamamos la atención aquí sobre las mismas por dos razones. Por un lado, como hemos dicho, implicaron una amplia utilización del espacio público en un contexto signado por el terror estatal. Por otro lado, las estrategias de juego y diversión, en cierta medida, se corrían del paradigma militar y eclesiástico, público y hegemónico, que hemos analizado ampliamente.

En este sentido, el diario La Nación informaba, “se inició la semana del Niño (con encuentros de creatividad infantil en dibujo, pintura, modelado, collage y mensajes de amistad para los niños del interior) que finalizará el sábado con un acto en el que hablará la subsecretaria del Menor y la Familia, Graciela Borzone” ( $L a$ Nación, 30/07/1979). Estas actividades se llevaban a cabo en el parque Rivadavia y estaban organizadas por la mencionada Comisión Día del Niño presidida por Schiariti. En esa ocasión, participaron alrededor de 1000 niños de 6 a 12 años, 80 de los cuales pertenecían a los institutos de menores dependientes de la secretaría del Menor y la Familia (La Nación, 30/07/1979). $\frac{15}{15}$ El "Día del niño” era también llamado "Día de la creatividad" y, con ese espíritu, se entregaba gratuitamente a los participantes cartones, temperas, arcilla y otros materiales donados por distintas empresas. En ese marco, sin embargo, las animaciones estuvieron a 
cargo de grupos católicos como, por ejemplo, los payasos de Salta del grupo “León Bravo”, llamados así en homenaje a un sacerdote salesiano de la provincia. A su vez, musicalizaba el espectáculo el grupo folklórico "Los juglares Sureños”, de la ciudad bonaerense de Necochea, y el grupo cristiano de folklore, "Conjunto Amistad”, de Lanús. Todos los días, durante una semana, se programaron actividades y el anteúltimo día se realizó un acto en la Plaza del Congreso, en donde actuó la banda filarmónica de la municipalidad de la Ciudad de Buenos Aires y de allí partió, luego, a modo de procesión, la "Ruta de la solidaridad” organizada por Schiariti hacia distintos hospitales y centros de rehabilitación, con juguetes, libros, golosinas y canciones para obsequiar a los niños internados (La Nación, 4/7/1979).

La "semana del niño" cerró un domingo con la "fiesta mayor del niño" en el Italpark, con acceso gratuito al evento y a los juegos del parque. Ese día "niños de diversas colectividades extranjeras que habitan nuestro país llevarán atuendos típicos y presentaran sus bailes regionales”. Al final del evento, se realizó una ronda de amistad de todos los niños. Entre los animadores de la fiesta estaban la banda de música de la Gendarmería nacional, los payasos "León Bravo", María Elena Schiariti y el conjunto "Jugando con el cuerpo” de Perla Laske, $\underline{16}$ el teatro Eckos, el mago Nordaac, los “Seglares sureños” de Necochea, el coro de Nuestra Señora de Fátima, los conjuntos de danza y música de colectividades extranjeras, y una exhibición de fútbol infantil por parte de los niños de los Institutos dependientes de la secretaría del Menor y la Familia y del club Vélez Sarfield (La Nación, 4/7/1979: 5/8/1979, La Nación; 6/8/1979).

Luego se sumaron diversas entidades de la sociedad civil a los festejos organizados, proponiendo actividades muy diversas. Por ejemplo, la Asociación Cerealistas de Buenos Aires organizó un festival infantil en la Bolsa de Cereales de Buenos Aires con entrada gratuita en donde se presentaron Rafael Carret y Pipo Pescador; las "entidades de bien público" de Belgrano y Núñez realizaron un concurso de manchas para niños de 4 a 12 años, sirvieron un "asado de la solidaridad”, organizaron un juego llamado "búsqueda del tesoro” y proyectaron películas; la asociación vecinal de fomento el "Talar norte” del barrio de Agronomía proyectó películas infantiles, presentó números artísticos y repartió entre los niños asistentes juguetes y golosinas donadas por firmas de la zona. Las entidades del barrio de La Paternal realizaron distintas actividades: el club Añasco, organizó un paseo en caballos ponis; el club Sholem Aleijem, un concurso de manchas; el club Raulíes, visitas guiadas a lugares históricos de la Ciudad de Buenos Aires. El Banco Credicoop, sucursal Villa Pueyrredón, proyectó cine infantil, la Asociación Atlética Argentino Junior brindó entretenimientos atléticos y la actuación de la banda del Regimiento de Infantería $\mathrm{N}^{\circ} 1$ Patricios ( La Nación, 4/7/1979; 5/8/1979).

Como vemos, por un lado, encontramos a la Iglesia, a las Fuerzas Armadas y miembros civiles de la elite tradicional proponiendo actividades que respondían a una difusa estrategia de socialización de la infancia con rasgos autoritarios de disciplinamiento. Por otro lado, junto a estas propuestas aparecen otras que, apuntando a celebrar el "Día de la creatividad", aunque sin tener un contenido demasiado alternativo, proponían un enfoque didáctico y lúdico que se diferenciaba de las primeras. No hay una estrategia unívoca que responda solamente al imaginario hegemónico pronunciado desde las altas esferas del poder. Además, todo esto ocurre en el espacio público, en plazas, parques de diversiones, en la calle, en dependencias públicas. Este despliegue nos brinda un panorama festivo de apropiación del espacio público, protagonizado por actores diversos pero impulsado desde el Estado. Esto nos permite no sólo dialogar con el conjunto de trabajos que han demostrado la existencia de diversas actividades en la esfera pública durante el terrorismo de Estado, $\frac{17}{2}$ sino también preguntarnos por las estrategias de legitimación y construcción del poder en ese contexto. Cabe señalar que el Estado no actuó en todas las áreas de manera monolítica, infalible y hermética, sino que, los límites entre Estado y sociedad eran porosos, difíciles de delimitar y la distancia entre lo público y lo privado se tornaba difícil de discernir. 


\section{Conclusión}

El propósito de este artículo fue dar cuenta de las representaciones sobre la niñez que tuvieron lugar en distintos ámbitos estatales, militares, religiosos y sociales durante la dictadura más represiva y autoritaria de la historia argentina. El problema de la infancia y la juventud adquirió una fuerte trascendencia en ese contexto, ya que entre los funcionarios civiles y militares existía la convicción de que la presunta crisis de la familia nuclear era una de las causas de la penetración del "virus subversivo" en el entramado social, a través de los menores, o sea, las “paredes” más débiles de la familia. Los niños, en particular, fueron objeto de una atención atenta por parte del régimen ya que, al ser considerados el "futuro de la patria” con toda la fuerte carga de incertidumbre amenazante que ello implicaba, se creía necesario formarlos en el ideario católico y nacionalista defendido por diferentes sectores del gobierno, la Iglesia y grupos del laicado.

Aún así, como vimos, la peculiar conexión -con sus ribetes trascendentales, incomprensibles e inmanejablesentre la infancia, el futuro y las nuevas tecnologías excedía a la coalición de derecha que ocupó el poder, y formaba parte de un sentido común más amplio de los años sesenta y setenta. En ese sentido, es posible afirmar que la niñez estuvo en el centro de las preocupaciones de diferentes actores sociales y estatales y fue objeto de iniciativas variopintas, algunas de las cuales intentamos analizar.

Los eventos a propósito del “Año internacional del niño” nos permitieron, así, abordar las propuestas existentes en el Estado y en el espacio público destinadas a ese grupo etario. Pudimos observar dos grandes tendencias. Por un lado, la propuesta de la coalición gobernante con sus tintes fuertemente elitistas, deportivos, militares y católicos que estaban en sintonía con el programa ordenancista y autoritario más difundido del gobierno. Pero, como vimos, y partiendo del propio Escardó, por otro lado, también había actores que proponían miradas alternativas sobre los niños, y estrategias lúdicas y festivas, que tuvieron una importante presencia y se contraponían al paisaje oscurantista diseñado por las autoridades. En relación con esto, unos y otros, en esos años duramente represivos, además de convivir, mostraban una fuerte presencia en las calles, plazas y diversas dependencias oficiales. De esta manera, además de realizar una contribución a la comprensión de las iniciativas hacia los niños durante la dictadura, este artículo también se propuso hacer un aporte al estudio de las formas de sociabilidad y apropiación del espacio público en los años más violentos del terrorismo de estado.

\section{Notas}

1 Era un programa televisivo producido por Jack Feldbaum y Gladys Muiño, conducido por Cristina Banegas, que se televisaba por Canal 13 los domingos la mediodía. Estaba conformado por 12 preadolescentes que cantaban distintos temas que combinaban el discurso predominante más reaccionario de la dictadura con estas ideas ligadas a los niños del futuro, el espacio exterior y la modernización tecnológica. Además, estos niños se autodenominaban "los niños periodistas", ya que entrevistaban a diferentes personalidades de la política, por ejemplo, al propio Videla. El programa se llamaba "buenos anuncios", por esta vocación periodística que demostraban y también porque buscaban transmitir valores de cara al mundo y al futuro como la "paz” contra la "guerra” y el "amor” contra el "odio”. Es interesante destacar que una de las canciones más populares que interpretaban, llamada "Si todos los niños del mundo", fue elegida por UNICEF como canción oficial del "año internacional del niño y la familia” en el año 1979. En el marco de un festival realizado en ocasión de celebrar el año del niño, el ministro de Bienestar Social, Jorge Fraga, entregó a tres "niños periodistas" credenciales como "periodistas" de la cartera (Boletín MBS, No 133-134$135,14-21-28 / 05 / 1979)$.

$\underline{2}$ En otras canciones como "Niños al espacio", aparecen representaciones similares. La letra de esa canción 
ilustra un viaje al espacio en que los niños van a visitar a El Principito y se combina la idea de los niños astronautas con un mensaje ligado a la situación política del país: "lo invitaremos [a El Principito] a que vuelva a visitarnos cuando la paz haya vencido a la guerra a festejar con los niños del mundo la llegada del 2000 a la tierra”. Es interesante tener en cuenta que El Principito estaba prohibido en estos años.

$\underline{3}$ Un abordaje más exhaustivo sobre el particular lugar que Escardó y su esposa Eva Giberti ocuparon en el campo de la pediatría puede encontrarse en Cosse (2010).

4 En una nota de opinión titulada "Los niños del 2000" tomaba posición sobre esa definición: "Una vieja definición repetida machaconamente ha postulado que la familia es la célula de la sociedad. Comparación o alegoría. La sociedad es un conjunto de familias tal como el tejido es un conjunto de células. Moraleja: cuidando la familia se cuida la sociedad. El más somero examen demuestra que no es así. En primer lugar, coinciden en la comunidad tipos bien diferentes de familia: la monogámica continua, la discontinua, la matrilocal...de modo que la palabra no se refiere ya a un conjunto unitario” (La Nación, 22/12/1979).

$\underline{5}$ En otra nota, este pediatra señalaba que la niñez no debía ser objeto de políticas específicas, porque el niño "es mucho más que su presencia actual, es inescapablemente la generación venidera es decir, la inmediata continuidad biológica, psicológica y moral del fluir de la humanidad. Cuanto sucede al niño sucede a la sociedad entera, al género humano entero”. Es decir, entendía al niño como la humanidad en su porvenir inmediato. En este sentido, criticaba a la asamblea de las Naciones Unidas al proclamar los Derechos del Niño como una declaración específica y diferenciada, ya que el documento "da la idea de alguien que advierte a los hombres 'pórtense bien con los niños', en vez de decirles: 'pórtense bien con ustedes mismos porque los niños son ustedes mismos el día de mañana”. Y proseguía "cuanto se hace por los niños aparece como algo dadivoso y caritativo y nunca como la elemental acción exigitiva a lo que ha de suceder a los adultos mañana mismo”, y criticaba la iniciativa de UNICEF, para el año 1979, que luego analizaremos: “cuanto más “días del niño” y "años del niño” se determinen y proclamen más queda en evidencia la exclusión resuelta que el adulto hace de su propio porvenir inmediato. Típica actitud de una sociedad suicida y, por peregrino que parezca, el modo más concreto de alterar la ecología de la humanidad” (La Nación, 31/08/1979).

$\underline{6}$ El Cuerpo de Vigilancia Juvenil (CVJ), dependiente de la Secretaría del Menor y la Familia del Ministerio de Bienestar Social, se encargaba de patrullar las calles en busca de menores de edad y los devolvía a sus familias, los llevaba a hospitales o a institutos de menores. Desde el Boletín semanal del MBS, el CVJ, además de dirigir preguntas a los padres (“¿Tiene conocimiento de los lugares que frecuenta su hijo? ¿Sabe si su moral e integridad física están resguardadas?”), publicaba con orgullo el número de menores “rescatados” de la vía pública y que, luego, eran o entregados a sus padres. Si los padres no sabían qué hacían o dónde estaban sus hijos, el Cuerpo "colaboraba" "en el mismo sentido de protección a los menores. En lugares de gran afluencia de público ejerce vigilancia diariamente para evitar el riesgo físico o moral de niños y jóvenes” (Boletín MBS N² 24, 07/02/1977).

$\underline{7}$ Ver reflexiones del pedagogo Pablo Scharagrodsky (Clarín, 28/05/2010).

$\underline{8}$ Además de tenista, fue campeón argentino de natación y representante de waterpolo del Club Universitario de Buenos Aires. Fue juez de la Cámara Nacional de Apelaciones del Trabajo -de la que también fue titulary miembro del Jurado de Enjuiciamiento de Magistrados de la Nación. Fue titular, en dos oportunidades, de la Asociación Argentina de Tenis (1967-73 y entre 1979-80), además de haber sido árbitro de la Copa Davis y de haber ejercido la vicepresidencia de Club Universitario de Buenos Aires (CUBA), entidad de la que, además, integró el Tribunal de Honor. Su figura es recordada en estos términos: “Aquel hombre que de lunes a viernes cumplía con sus obligaciones laborales en la oficina abarrotada de legajos en pleno centro de la ciudad y a pocos metros del Obelisco, fue el factótum de una época de esplendor de esos gajos de polvo de 
ladrillo que se abren como un surco entre la calle Olleros y las vías del Ferrocarril Mitre” (La Nación, 01/10/2004).

$\underline{9}$ Ver el homenaje que la "Fundación Nuestro mar" realizó a su personalidad en: http://www.centronaval.org.ar/boletin/BCN833/833-PUGLISI.pdf.

10 Laura Rodríguez (2009) muestra que, a partir de 1978, la Subsecretaría de Educación de la provincia de Buenos Aires adhirió a la conmemoración del Día del Comportamiento Humano (31 de marzo). En las escuelas debía recordarse ese día. Para esto, se distribuyeron textos sobre a la familia que habían sido preparados por la Secretaría de Información Pública (derechos y obligaciones y la familia) y por la Liga de la Fundación Rizzuto (día del comportamiento humano). En este sentido, siguiendo a Rodríguez, la circular de la Subsecretaría afirmaba que "ese día se exaltaban los 'valores éticos, morales y espirituales' que conformaban 'nuestro estilo de vida’ y disponía que en todas las escuelas de la provincia se diera lectura al mensaje del señor Ministro de Educación. El mandatario advertía que se vivían tiempos en los que la violencia, la destrucción de personas y bienes y la desintegración de la familia eran problemas que afectaban a toda la sociedad y que ellos - los militares- venían a solucionar”. También se recordaba el fallecimiento del fundador de la liga, Rizzuto.

11 También consiguió que se festejara todos los años el "Día del niño" y el "Día de los reyes magos", llevando a hospitales, centros de atención a la niñez e institutos de la minoridad, y entregando en mano un regalo a cada niño internado. Además, en dichos lugares, en las Fiestas Patrias del 25 de Mayo y 9 de Julio, organizaba certámenes, concursos de collages, etc. y entregaba diplomas a los participantes, como así también escarapelas, banderitas, útiles escolares y golosinas. Por último, incorporó a la comisión el "Día del ahijado", cuyo su festejo se realiza el segundo domingo de mayo. En todas las actividades imponía el logotipo de la Comisión Ejecutiva "Día del Niño” y su lema “el niño lo merece todo".

12 Laura Rodríguez (2009) muestra que en 1980 la Subsecretaría de Educación adhirió a la Campaña Nacional de Comunicación Social "El niño, la Escuela y el Ejército” para las escuelas primarias. La iniciativa disponía un conjunto de tareas que tenían el propósito de informar a los alumnos sobre la historia del Ejército argentino, sus orígenes y trayectoria, y "desarrollar actitudes que permitieran valorarlo como institución fundamental de la Nación”.

$\underline{13}$ Creada por el Ejército en el marco de la denominada “Campaña al Desierto”.

$\underline{14}$ En la jornada de apertura dio una conferencia el presidente del Episcopado argentino, cardenal Francisco Primatesta.

15 Domingo Faustino Sarmiento (primaria), San Martín (ingreso), Borzas de Otamendi (ingreso) y Crecencia Boado de Garrigós (6 a 12 años).

16 María Elena Schiariti, hija de Oscar Schiariti, pertenecía a grupos de teatro para niños, como el de Perla Laske, que tenían una propuesta que en la época era alternativa. En palabras de Laske: "para mí el teatro infantil tiene que ser teatro-juego. El niño tiene que ser protagonista de lo que se está dando y tener una coparticipación en el hecho actoral” (Zayas de Lima, 1991).

17 Distintos trabajos han intentado desmitificar las imágenes más asociadas con la cultura del miedo en el contexto del terrorismo de Estado a partir del análisis de las actitudes de grupos sociales diversos y la activa apropiación del espacio público (Lida, 2008; Kahan, 2014). 


\section{Bibliografía}

Aguirre, O. (2010). La Alianza para el Progreso y la promoción del desarrollo en América Latina. Revista Afuera, 5 (9). Recuperado de: http://www.revistaafuera.com/autores detalle.php?id=94.

Altamirano, C. (1998). Desarrollo y desarrollistas. Prismas Anuario de Historia Intelectual, 2, pp. 75-94.

Anich, M. (s.f.). Profesor Oscar Schiariti. Su obra en favor del niño y del adolescente. Recuperado de: http://studylib.es/doc/172840/profesor-oscar-nicolas-schiariti--su-obra-en-favor-del-ni.

Cosse, I. (2010). Pareja, sexualidad y familia en los años sesenta. Buenos Aires: Siglo XXI Editores.

Di Stefano, R. y Zanatta, L. (2009). Historia de la Iglesia Argentina. Buenos Aires: Sudamericana.

Guitelman, P. (2006). Infancia en dictadura, modernidad y conservadurismo en el mundo de Billiken. Buenos Aires: Prometeo.

Kahan, E. (2014). Recuerdos que mienten un poco. Vida y memoria sobre la experiencia judía durante la última dictadura militar. Buenos Aires, Prometeo.

Feldbaum, J. (1979). Suplemento 2000. En Los niños periodistas [disco]. Buenos Aires: Phono Musical Argentina Diorama.

Filc, J. (1997). Entre el parentesco y la política. Familia y dictadura, 1976-1983. Buenos Aires: Biblos.

Lida, M. (2008). Las masas católicas en los años de la dictadura, 1976-1982. Entrepasados. Revista de Historia, 34, pp. 55-73.

Lvovich, D. y Rodríguez, L. (2011). La Gendarmería Infantil durante la última dictadura. Quinto sol, 15 (1), pp. 165-184.

Osuna, M. F. (2016). La intervención social del Estado argentino entre dos dictaduras. Un estudio de los proyectos, las políticas y los actores del Ministerio de Bienestar Social/Acción Social de la Nación (19661983). Facultad de Filosofía y Letras, Universidad de Buenos Aires, Ciudad de Buenos Aires, Argentina.

Rodríguez, L. (2009). La Historia que debía enseñarse durante la última dictadura militar en Argentina (1976- 1983). Antíteses, 2 (3), pp.227-256.

Villalta, C. (2005). La apropiación de menores: entre hechos excepcionales y normalidades admitidas. En A. Lo Giúdice, (Comp.), Psicoanálisis. Restitución, apropiación, filiación (pp.175-199). Buenos Aires: Abuelas de Plaza de Mayo.

Villalta, C. (2009). De secuestros y adopciones: el circuito institucional de la apropiación criminal de niños en Argentina (1976-1983). Historia Crítica, 38, pp. 46-171.

Villalta, C. (2013). Estrategias políticas y valores locales. El impacto de la apropiación criminal de niños en la sociedad argentina. En V. Llobet, (Comp.), Pensar la infancia desde América Latina: un estado de la cuestión, (pp. 185 - 207). Buenos Aires: CLACSO.

Villalta, C. y Regueiro S. (2015). Una densa trama jurídico-burocrática: el circuito institucional de la apropiación criminal de niños. En J. P. Bohoslavsky, (Comp.), ¿Usted también, doctor? Complicidad de jueces, fiscales y abogados durante la dictadura (pp. 163 - 179). Buenos Aires: Siglo XXI editores.

Villalta, C. (2016). Circuitos institucionales y tramas de relaciones sociales: las formas de materialización de la apropiación criminal de niños. En G. Águila, S. Garaño y P. Scatizza, (Comps.), Represión estatal y violencia paraestatal en la historia reciente argentina: nuevos abordajes a 40 años del golpe de Estado (pp. 296 - 318). La Plata: Universidad Nacional de La Plata. 
Zayas de Lima, P. (1991). Diccionario de autores teatrales argentinos, 1950-1990. Buenos Aires: Galerna. 